Applied Composite Materials

Volume 14, Number 1 / January, 2007; Pages 67-87

http://dx.doi.org/10.1007/s10443-006-9033-8

C2007 Springer Science+Business Media

The original publication is available at http://www.springerlink.com
Archimer, archive institutionnelle de l'Ifremer http://www.ifremer.fr/docelec/

\title{
Damage Resistance of Composites Based on Glass Fibre Reinforced Low Styrene Emission Resins for Marine Applications
}

\author{
Y. Perrot ${ }^{1{ }^{*}}$, C. Baley ${ }^{1}$, Y. Grohens ${ }^{1}$ and P. Davies ${ }^{2}$
}

(1) Université de Bretagne Sud, L2PIC, BP 92116, 56321 Lorient, Cedex, France

(2) IFREMER, Materials \& Structures group (ERT/MS), BP70, 29280 Plouzané, France

*: Corresponding author : yves.perrot@yahoo.fr

\begin{abstract}
Composites based on glass fiber reinforced low styrene emission polyester resins have been widely used over the last 10 years, in order to meet increasingly strict safety regulations, particularly in the pleasure boat industry. Previous studies of their mechanical properties suggested that although these resins are generally more brittle than traditional orthophthalic polyester resins this did not adversely affect the properties commonly used for quality control (short beam shear and tensile failure strength of mat reinforced composites). In the present paper results from a more detailed study of damage behaviour are presented. Tests include fracture toughness $\left(K_{l c}\right)$ tests on resins, fibre/matrix interface energy, detection of composite damage initiation in tension by acoustic emission, composite delamnation ( $G_{i c}$ and $G_{\| c}$ ), and low energy impact. Overall the results indicate that the low failure strain of low styrene emission resins results in significantly lower composite damage resistance.
\end{abstract}

Key words: glass fibers - unsaturated polyester - styrene emission - damage initiation - interface properties 


\title{
Damage resistance of composites based on glass fibre reinforced low styrene emission resins for marine applications.
}

\author{
Y. Perrot*, C. Baley*, Y. Grohens*, P. Davies** \\ *Université de Bretagne Sud, L2PIC, BP 92116, 56321, Lorient, Cedex, France \\ **IFREMER, Materials \& Structures group (ERT/MS), BP70, 29280 Plouzané, France,
}

\section{Introduction}

Polyester resins are still by far the main matrix polymers used for pleasure boat construction, and the principal manufacturing method remains wet lay-up. In order to satisfy health and safety regulations on the levels of acceptable volatiles in boatyards the resin suppliers have adapted their formulations. Three types of resin are proposed:

- Low styrene content polyesters. The styrene content is reduced, but in order to keep viscosity low the molecular weight of the pre-polymer is also reduced.

- Low styrene emission resins. Additives are included which migrate to the surface to form a film limiting styrene emission (e.g. wax, paraffin).

- Mixed resin formulations, low styrene content and low emission.

An alternative approach is to replace the styrene with another solvent, but this generally results in higher cost and requires extensive testing to ensure non-toxicity.

The properties of glass fibre reinforced composites for marine applications depend on many factors. Their mechanical behaviour is strongly dependent on the fibre orientations and their volume fraction. The matrix plays an important role to ensure the geometry and protect the reinforcement. The load transfer through the fibre-matrix interface may also be critical. In a previous study Baley et al. [1] showed the influence of curing conditions (time, temperature) on the mechanical properties of unreinforced polyester resins. That study showed significant differences between standard polyester resins and polyesters formulated to limit styrene emissions. All were commercial products, and the latter showed much lower strains to failure in tensile tests. Tensile tests on glass mat reinforced composites in that work showed little influence of resin brittleness on composite failure properties however. In the present study 
this is further examined, but the accent here is on damage initiation and development before final failure. The aim is to establish to what extent users need to be concerned by the more brittle nature of low styrene resins, given that the most widely used tests do not appear to be sensitive to it. This also poses questions concerning the choice of tests and the relevant scale (microscopic or macroscopic) to evaluate this type of material.

\section{Materials and test procedures}

\subsection{Resins and reinforcements}

Seven commercial resins were chosen for this study, supplied by the three main suppliers of resins for wet lay-up at boatyards in France : two standard orthophthalic polyesters (SO1 and SO2), two orthophthalic DCPD low styrene content polyesters (LS1 and LS2), two mixed orthophthalic DCPD low styrene content and low emission polyesters (LES1 and LES2) and a standard vinylester (SV1). In the text all the polyesters formulated to reduce styrene emissions (LS1, LS2, LES1, LES2) will be identified as "reduced styrene" resins. It should be emphasized that such resins are widely used today to produce boat hulls and decks. Table 1 shows styrene levels provided by suppliers, together with tensile properties measured by the authors [1]. The low failure strains of the RS resins are apparent as mentioned above.

For tests on composites, four types of E-glass reinforcement were used here :

- $\quad 300 \mathrm{~g} / \mathrm{m}^{2}$ chopped strand mat

- $\quad 500 \mathrm{~g} / \mathrm{m}^{2}$ balanced weave (taffetas)

- $\quad 300 \mathrm{~g} / \mathrm{m}^{2}$ unidirectional

- $300 / 500$ rovimat $\left(300 \mathrm{~g} / \mathrm{m}^{2}\right.$ of mat stitched to a $500 \mathrm{~g} / \mathrm{m}^{2}$ taffetas).

These reinforcements all have polyester compatible sizing. The composites were produced by wet lay-up, compacted either manually with a roller or in a hydraulic press. In the latter case the thickness (and hence the fibre content) was controlled by spacers.

In all cases the materials (resins and composites) were manufactured at laboratory temperature $\left(20 \pm 2^{\circ} \mathrm{C}\right)$ with $1.5 \%$ MEKP catalyst, as recommended by the suppliers. They were then post-cured using a cycle of 24 hours at room temperature then 16 hours at $40^{\circ} \mathrm{C}$. This cure cycle was chosen as it was shown to correspond to a cure state similar to that obtained on industrial components [1]. For tests on unreinforced resins specimens were 
machined from cast plates. This enabled a good surface finish to be obtained and low porosity. For the composites fibre content was determined by burn-off according to standard method NF T 57 102, heating for 1 hour at $650^{\circ} \mathrm{C}$.

\subsection{Mechanical test methods}

\section{Fracture toughness of resins}

The resin fracture toughness was determined using three point bend tests on notched beam specimens according to standard test method ISO 13586 [2]. Parallel sized notched specimens of thickness $B$ and width $W$ satisfied the following requirements:

$-4 B \geq W \geq 2 B$,

- span length $L=4 W$,

- notch length $a$ such that $0.45<a / W<0.55$.

The loading rate was $10 \mathrm{~mm} / \mathrm{min}$. Five specimens were tested for each resin. Loaddisplacement plots were linear and the maximum load $F_{\max }$ was used to calculate the critical stress intensity factor $K_{l c}$ in the expression [3] :

$$
K_{I c}=\frac{3 F_{\max } L}{B W^{2}}\left(\frac{\pi W}{2}\right)^{1 / 2}
$$

Knowing their elastic properties the critical strain energy release rate can then be calculated from the measured $K_{I c}$ value using the following expression:

$$
G_{I c}=\frac{K_{1 c}}{E}\left(1-v^{2}\right)
$$

To obtain $G_{l c}$ a value of Poisson's ratio of 0.35 was used.

Note that the standard test method recommends using a pre-notch made by a saw-cut then initiating a natural crack by tapping with a new razor blade. For the very brittle resins tested here this proved impossible, so in order to be able to compare all the resins with the same notch geometry all notches were prepared using a fine saw and no natural crack. The crack tip radius is estimated to be $0.5 \mathrm{~mm}$ (Figure 1). 


\section{Debonding tests}

The apparent shear strength of the fibre/matrix interface was measured by the microdroplet debond test [4]. This involves measuring the force necessary to separate a microdroplet of cured resin from a single fibre. The diameters of the fibre $d_{f}$ and the droplet $d_{g}$ together with the bonded length $l_{e}$ are measured using an optical microscope and image analysis (Microscope LEICA / Qwin Software). The geometry (symmetry and absence of defects) of each droplet is checked. Tests were performed on a test machine (MTS Synergie 1000) with a $2 \mathrm{~N}$ load cell at a loading rate of $0.1 \mathrm{~mm} / \mathrm{min}$.

To a first approximation, an apparent mean shear strength of the interface $\tau_{\text {app }}$ is calculated (the shear stress distribution is assumed constant along the interface). This value is obtained either by averaging the experimental stress values or by linear regression, plotting the debond load versus debond area, the interfacial shear stress corresponding to the slope of the line [4]. The apparent shear strengths from the two methods are usually quite similar.

Scheer [5] presented an alternative analysis of the data from these tests, which allows an interfacial fracture energy to be estimated,based on results from the shear lag analysis :

$$
\mathrm{F}_{\mathrm{d}}=\pi \mathrm{r}_{\mathrm{f}}^{2}\left(\sqrt{\frac{2 \mathrm{G}_{\mathrm{ic}}}{\mathrm{r}_{\mathrm{f}} \mathrm{C}_{33 \mathrm{~s}}}}-\frac{\mathrm{D}_{3 \mathrm{~s}} \Delta \mathrm{T}}{\mathrm{C}_{33 \mathrm{~s}}}\right)
$$

$F_{d}:$ debond force

$r_{f}:$ radius fibre

$d_{f}=2 r_{f}:$ diameter fibre

$\Delta T$ is the difference between the stress-free temperature and the specimen temperature $G_{i c}:$ interfacial toughness

$\mathrm{D}_{3 \mathrm{~s}}=\frac{1}{2}\left(\alpha_{\mathrm{fA}}-\alpha_{\mathrm{m}}\right)$

$\alpha_{f a}$ : axial coefficient of thermal expansion of fibre

$\alpha_{m}$ : coefficient of thermal expansion of matrix 
$C_{33 S}=\frac{1}{2}\left(\frac{1}{E_{f A}}+\frac{V_{1}}{V_{2} E_{m}}\right)$

$E_{f A}$ : longitudinal Young modulus of fibre

$E_{m}$ : Young's modulus of matrix

$V_{l}$ : volume fraction of the fibre

$V_{2}$ : volume fraction of the matrix

$V:$ droplet volume

The droplet/fiber region of the specimen is assumed to be an ellipsoid with total volume :

$V=\frac{4 \pi}{3}\left(\frac{D_{g}}{2}\right)^{2}\left(\frac{L_{e}}{2}\right)$

$D_{g}=2 r_{g}:$ droplet diameter

$L_{e}$ : embedded length

The volume fraction of the fiber is then :

$V_{1}=\frac{\pi r_{f}^{2} L_{e}}{V}=1.5\left(\frac{r_{f}}{r_{g}}\right)^{2}=1.5\left(\frac{d_{f}}{D_{g}}\right)^{2}$

$r_{f}:$ radius fiber $r_{f}=d_{f} / 2$

The fibre stress is :

$\sigma_{\mathrm{fd}}=\frac{\mathrm{F}_{\mathrm{d}}}{\pi \mathrm{r}_{\mathrm{f}}^{2}}$

The interfacial toughness $G_{i c}$ is :

$G_{i c}=\frac{r_{f}}{2}\left(C_{33 s} \sigma_{f d}^{2}+2 D_{3 s} \sigma_{f d} \Delta T+\frac{D_{3 s}^{2}}{C_{33 s}} \Delta T^{2}\right)$ 
$G_{i c}$ is only an interfacial toughness when the failure mode is at the interface. This expression was used to estimate the interface fracture energy here.

\section{Short beam shear on composites}

Interlaminar shear tests were performed in three point bending on short beams. The standard test procedure of ISO 4585 was followed on a test machine (MTS Synergie RT 1000) with a $10 \mathrm{kN}$ load cell. The specimens had a width $b$ of $20 \mathrm{~mm}$ and thickness $h$. The distance between supports was 5 times the thickness. This is a simple and widely used test providing an apparent shear strength using the force at failure $F$ in the expression:

$$
\tau=\frac{3 F}{4 b h}
$$

\section{Tension on composites}

Composite tensile tests were performed according to standard NF T 57101 with the same test machine as for the interlaminar shear tests. Parallel sided specimens were tested of width 20 $\mathrm{mm}$ and length $200 \mathrm{~mm}$. Loading rate was $2 \mathrm{~mm} / \mathrm{min}$ and a Hansfield HSC extensometer was used to measure displacements. The appearance of damage was detected by an EPA (Euro Physical Acoustics) acoustic emission system, with Mistras software. The signals are detected and located (to avoid parasite signals) by two piezoelectric transducers (EPA Pico 3461, 500 $\mathrm{Hz}$ ) pre-amplified $(P A C 1220 A)$ by $40 \mathrm{~dB}$. Liquid soap was used to improve coupling between specimens and transducers.

\section{Interlaminar fracture}

Mode I delamination resistance was measured on DCB (Double Cantilever Beam) specimens. These contained a starter film at mid-thickness ( $8 \mu \mathrm{m}$ thick PP film) inserted during manufacture. Aluminium end blocks were bonded to specimen ends for load introduction (Figure 2a). This type of test, recently standardized [6], allows the initiation and propagation of cracks to be followed from the end of the starter film. Tests were performed at $2 \mathrm{~mm} / \mathrm{min}$ on an Instron 4302 test machine with a $500 \mathrm{~N}$ load cell. The specimen geometry is as follows :

- thickness $h=5-6 \mathrm{~mm}$

- $\quad$ width $b=20 \mathrm{~mm}$ 
- $\quad$ length $L=200 \mathrm{~mm}$

- $\quad$ starter crack length $a=50 \mathrm{~mm}$

During the test the crack length $a$ is recorded together with the load applied $F$ and the opening displacement $\delta$. The strain energy release rate $G_{l}$ is used to characterize the delamination resistance. A critical value is defined at initiation, $G_{l c}$, determined here as the onset of nonlinearity then during propagation further values are determined, $G_{l p}$, as a function of crack length. Here, Berry's method was used to determine $G_{I}$, [7], using the following expression :

$G_{1}=\frac{n F \delta}{2 b a}$

where $n$ is the slope of a plot of $\ln (C)$ versus $\ln (a)$, with $C$ the compliance $(\delta / F)$ at each crack length.

Mode II delamination resistance was measured using the 4ENF (four point end notched flexure) specimen proposed by Martin \& Davidson [8], Figure 2b.Crack length is determined visually during the test. The strain energy release rate $G_{1 I}$ is then determined using the following equation :

$G_{I I}=\frac{F^{2} m}{2 b}$

where $m$ is the slope of a plot of $C$ versus $a$, with $C$ the compliance $(\delta / F)$ at each crack length.

\section{Impact tests}

In order to examine the behaviour of laminates under dynamic loading, of direct interest in the application of composites for boat structures, a series of drop weight impact tests was performed. Figure 3 shows the experimental set-up. A steel projectile, of mass $1.6 \mathrm{~kg}$ and 150 $\mathrm{mm}$ long with a hemispherical tip of $50 \mathrm{~mm}$ diameter, is released from different heights and descends down a guide rail before impacting the composite panels. The impacter is instrumented with a piezoelectric accelerometer (Endevco 2255B-1) placed inside the hemispherical tip. An anti-rebound device with an electromagnetic spring-loaded clamp is triggered when the impacter passes an infrared sensor for the second time. Two infrared sensors also allow the impact speed to be measured accurately. The panels tested were square of side $150 \mathrm{~mm}$, and were simply supported on a cylindrical steel support (outer diameter 142 
$\mathrm{mm}$ wall thickness $13 \mathrm{~mm}$ ). An oscilloscope was used to record acceleration (in $\mathrm{mV}$, then converted using a factor of $0.8483 \mathrm{mV} / \mathrm{g}$ ) and impact time.

All panels were inspected before and after impact using ultrasonic C-scan. Panels were immersed in a water tank and placed on a metallic reflector. The transducer (WS50-5-P2 / 5 $\mathrm{MHz}$ ) has a $1.1 \mathrm{~mm}^{2}$ focussed spot size at a distance of $25.4 \mathrm{~mm}$. It scans the specimen controlled by a Sofratest $\mathrm{x}-\mathrm{y}$ motor with a step of $0.5 \mathrm{~mm}$. Damage can be detected visually but the different colours of the two resins used in the composites impacted here made comparisons difficult, so the ultrasonic method was preferred. Damage is readily detected as a strong attenuation of the ultrasonic signal and projected damage zones can be plotted. Some panels were sectioned and polished, and a coloured penetrant liquid was used to reveal the nature of through thickness damage under ultraviolet light.

\section{Results and discussion}

\subsection{Resin properties}

These resins were characterized in some detail previously [1], Table 1, so here only results from a complementary series of fracture toughness tests are presented. The resin failure strains were shown to be lower than those of standard polyesters and vinyl esters, but tensile test failure strains are very sensitive to specimen surface finish and manufacturing defects. In order to confirm these results, and to provide fracture energy values for a discussion of damage tolerance, the critical stress intensity factor $K_{l c}$, and the critical strain energy release rate $G_{I c}$. The tests were performed on the four resins SO1, LS1, LES1 et SV1. Table 2 shows the results. The vinyl ester is clearly tougher than the polyesters but the DCPD polyesters LS1 and LES2 are less tough than the standard polyester. For comparison, Compston et al. [9] measured $K_{l c}$ values for a series of marine resins including the same vinyl ester. They found lower values than here, probably due to the natural precracks employed, but also indicated that the vinylester resin was tougher than orthophthalic and isophthalic polyesters.

These results confirm the brittle nature of the RS polyester resins. To illustrate this, the failure strains are plotted versus fracture energies, Figure 4. This shows that failure strain increases with $G_{l c}$ In other words, the capacity of the resin to limit crack propagation is higher for 
resins with higher failure strains. This suggests that the damage tolerance of the RS polyesters will be lower than that of the standard resins.

\subsection{Fibre/matrix interface properties}

The matrix response is one element which contributes to damage tolerance, fibre/matrix interface is another. The microdroplet debond test enables information on this region to be obtained. Tests were performed on single fibres taken from a balanced E-glass fabric (taffetas $500 \mathrm{~g} / \mathrm{m}^{2}$ ). Figure 5 shows an example of a load-displacement plot. The load increases linearly with displacement until it reaches a maximum which corresponds to interface crack propagation. Debonding is followed by friction between the droplet and the fibre, which indicates the presence of residual thermal stresses [10].

Table 3 shows the results for tests performed with four resins, (SO1, LS1, LES1 et SV1), using both the stress and energy analyses presented previously.

First, it is interesting to note that the droplet sample selection by microscopy has enabled a homogeneous set of droplets to be tested, similar ratios of bonded length/drop diameter have been tested for all four resins. The apparent shear stresses from the two analyses and the fracture energies $G_{i c}$ show very significant differences between the resins. The two RS polyesters (LS1 and LES1) show higher values than the standard polyester and vinylester resins SO1 and SV1.

The low value for the vinyl ester may be due to poor compatibility between the sizing on the glass and this resin, though there may also be a difference due to the microdroplet properties. Dirand et al. [11] have indicated that the mechanical properties of vinyl ester in microdroplets are poorer than those of the matrix in a composite due to evaporation of styrene during cure (as a result of the absence of mould and a large exchange area with the air).

These tests are interesting as they allow measurement of a property related to the integrity of the fibre/matrix interface directly, but the results must be treated with caution as there are many parameters which influence the results (elastic properties of the resin, fibre diameter, [12] bonded length and residual stresses [13] and droplet geometry [14].

\subsection{Composite properties}


There are two tests commonly used in the marine industry to evaluate fibre/matrix combinations, short beam shear and tensile tests. These were therefore performed first, as discussion with industrial partners had indicated that the results from these tests showed no reduction in composite performance when standard polyesters were replaced with reduced styrene resins.

\subsubsection{Interlaminar shear strength}

The first test performed was the short beam shear. This test is frequently used as a quality control check on marine composites, as it can be performed on specimens cut from boat structures [15]. However, the stress state in the specimen is complex and includes tension, compression and shear. The regions near the supports and the loading point are particularly difficult to analyse. Various parameters influence results, including fibre content, porosity, stacking sequence, boundary conditions, .... Several authors $[16,17]$ have indicated that this test is sensitive to resin type and fibre/matrix interface strength.

Two series of tests with different reinforcements were performed :

- 24 unidirectional fibres plies, impregnated then compacted in the press to around $48 \%$ fibre volume fraction.

- 5 mats and 4 woven taffetas. These composites, manually compacted, had a mean fibre volume content around $26 \%$. This is a common composite material for pleasure boat construction.

At least five specimens were tested for each condition. The apparent interlaminar shear strength (ILSS) values measured are presented in Table 4. These values, between 20 and 30 $\mathrm{MPa}$, are typical of those found for this type of material [18]. It is interesting to note that the two sets of materials do not give the same values. The first series (30 $\mathrm{MPa})$, with a significantly higher fibre content and only unidirectional fibres, has a higher ILSS than the second (20 MPa). The influence of fibre content and reinforcement type are thus apparent, but the results are not sensitive to the resin. This is important as it indicates that this kind of test cannot be used to discriminate between composites based on polyester resins with very different properties. Standard and low styrene polyesters give the same values.

\subsubsection{Tensile tests with acoustic emission to detect damage.}


In previous work [1], it was shown that the tensile failure strengths of mat reinforced composites were not affected by changing the type of resin used. That confirmed results from boatyards, who use this test to evaluate new resin formulations. However, it was also noted that the shape of the stress-strain plots varied with the type of resin and that non-linear behaviour occurred much earlier when reduced styrene resins were employed as matrix. In the present study these tests were therefore repeated, but using acoustic emission to detect initiation of damage processes.

Three polyesters (SO1, LS1, LES1) and a vinyl ester (SV1) were tested, all reinforced by glass mat (three $300 \mathrm{~g} / \mathrm{m}^{2}$ mat layers). Produced by hand lay-up their fibre volume content was around $18 \%$. For each resin 5 specimens were tested. Figure 6 shows an example of the stress-strain plots recorded, together with the cumulated acoustic emission hits.

The main difficulty with this method of damage detection is interpretation of the signals in terms of damage mechanisms. Composite materials are anisotropic and heterogeneous so the propagation, dispersion and reflection of acoustic waves is very complex. Nevertheless, for glass mat reinforced composites Meraghni \& Benzeggagh [19] have shown that it is possible to attribute amplitude intervals to different damage mechanisms. The zone between 40 and 60 $\mathrm{dB}$ appeared to correspond to the development of matrix microcracks. In the present tests a damage threshold was chosen (arbitrarily) as $50 \mathrm{~dB}$. Then, using this criterion, Table 5 shows the stress and strain levels for each material. Examination of these results shows that :

- The Young's moduli of the matrix resins and the composites are similar.

- The failure stresses of the composites are not influenced by the type of matrix. The small differences are due to scatter in hand lay-up materials.

- The stress and strain at the onset of damage are strongly dependent on the matrix. The resins formulated to reduce styrene emissions have lower failure strains, which cause early initiation of microcracks. When resin failure strain is higher first damage occurs later.

Meraghni et al. [19] showed that in similar polyester composites the first damage appeared in the matrix and corresponded to cracks in fibre bundles perpendicular to the loading direction. As strain increased these cracks propagated and caused interfacial debonding. Fibre breaks only occurred near final failure. The non-linearity observed on stress-strain plots for glass mat composites corresponds to the appearance and accumulation of damage. Figure 7 shows the relation between matrix failure strain, failure strain of a unidirectional (UD) composite loaded 
in the transverse direction and the acoustic emission damage threshold for mat composites. Both the latter increase with increasing matrix failure strain. It is also interesting to note that the failure strain for the transverse UD test is very close to the damage threshold noted in the mat composites. These results confirm the observations of Meraghni et al. [19].

\subsubsection{Interlaminar Fracture Toughness}

The previous series of tests indicated the role of the matrix in intralaminar damage initiation. Three polyester resins were then selected to examine the influence of the matrix on the delamination resistance of unidirectionally reinforced composites. These were a standard orthophthalic (SO2), a DCPD low styrene content (LS2) and a mixed DCPD with very low styrene content (LES2). The use of unidirectional reinforcement is necessary to obtain a sufficiently rigid specimen and avoid large displacements. The mean fibre volume content is $47 \pm 2 \%$. Three to five specimens were tested for each resin.

In general mode I propagation was stable from the starter film insert, except for the specimens of LES2. For these the crack propagated in a very unstable (stick-slip) fashion. Similar propagation has been described elsewhere, in resins and composites, and attributed to crack tip blunting followed by a jump when excess energy is released [21, 22]. The values of critical strain energy release rate at initiation defined by the onset of non linearity $G_{l c}$, are shown in Table 6.

The values obtained, in the range $80-120 \mathrm{~J} / \mathrm{m}^{2}$ are typical for this type of composite $[9,23]$. Given the scatter the differences between the three resins are probably not significant, suggesting that the use of RS polyesters does not affect $G_{l c}$ at initiation in unidirectional composites.

A second aspect of these tests is the behaviour during propagation. In the ISO standard test method propagation values are only measured in order to validate the initiation values, as previous studies showed that R-curve development and propagation values were influenced by specimen stiffness $[24,25]$. However, here the specimens have the same stiffness, only the matrix resin is varied, so the comparison between propagation values can provide useful information. It is common to plot $G_{I p}$ as a function of measured crack length, Figure 8 and Table 6. Here there are significant differences between the three resins. The polyesters SO2 and LS2 show similar stable propagation, with two parts to the curves : a first part during which resistance to propagation increases, then a second more constant part. The first part 
corresponds to the creation of a bridging zone as delaminations propagate in planes above and below the initial crack plane. Once this zone is in place it advances in front of the crack tip . For the $\mathrm{SO} 2$ polyester the energy required to propagate a crack in these unidirectional materials is around twice as high as that for the LS2 composite $\left(900\right.$ compared to $\left.500 \mathrm{~J} / \mathrm{m}^{2}\right)$. The third material, LES2, shows very unstable crack jumps and very little fibre bridging. In spite of the higher toughness of the standard polyester resin the initiation values of $G_{I c}$ measured here are very similar for the three materials. Initiation corresponds to the first damage at the crack tip and higher resin toughness is not transferred to the composite at initiation if the first damage occurs at the fibre/matrix interface. The microdroplet debonding results, which reveal a much lower interface debond energy for the standard resin, suggest that initiation $G_{I c}$ in those samples may be due to a debonding mechanism.

Once propagation starts the lower interface debond energy in the standard polyester will result in the formation of a damage zone with multiple debonds above and below the initial crack plane, shown schematically in Figure 9. Thisresults in extensive fibre bridging, the simultaneous propagation of several cracks and a higher apparent fracture energy. Several studies of fibre bridging have discussed the role of the fibre/matrix interface strength and a recent study of glass/polyester composites with weak and strong interfaces clearly showed that the composite with the weaker interface showed the higher toughness due to increased bridging [26]. In the LES2 material however, the main crack propagation mechanism involves single crack advance. This crack does not advance in a stable manner, but in unstable jumps. Fracture surfaces for the three materials revealed extensive fibre debonding in the $\mathrm{SO} 2$ and LS2 materials, with a very flat shiny surface for the LES2 composite.

Mode II testing is more controversial, and there is no standard test method today. Several tests exist [27] of which the 4ENF and ELS (End Loaded Split) configurations appear to be the most attractive, as they allow stable crack propagation. This is important not only as it enables the full R-curve to be obtained but also because the stability of propagation after first initiation from the starter film gives an indication of the validity of the test. Unstable initiation is often a sign of a starter film problem. The 4ENF test was selected here and tests were performed on the SO2 and LES2 materials. Results are shown in Table 7 and R-curves are plotted on Figure 10. These show that mode II delamination resistance is virtually identical for the two materials, despite their very different mode I performance. There is a tendency for resistance to increase with crack propagation for both materials, which may be the result of friction between the crack surfaces; no fibre bridging is noted during these mode II tests. 
There have been numerous studies of the transfer of toughness from resins to composites [9, $28,29]$. The relationship between resin and composite toughness is complex and depends on the type of tests employed and their analysis. It is interesting to note here that the significant difference in resin properties only appears to affect mode I propagation toughness of the composites, the other values characterising mode I and mode II delamination resistance are very similar. In order to investigate another aspect of the practical implications of using reduced styrene resins a series of drop weight impact tests was then performed.

\subsubsection{Plate impact}

The results presented above show various aspects of the damage resistance of reduced styrene polyester resins and their composites, compared to traditional polyesters. The common point is that they are all from material tests, which reveal different aspects of the resins and composites as a function of rather simple loadings. In practice the boatbuilder is concerned with how the boat structure will respond when the laminating resin is changed. In order to examine this aspect three panels, $600 \times 600 \mathrm{~mm}^{2}$, were hand laminated from a standard orthophthalic polyester (SO2), an orthophtalic DCPD low styrene content polyester (LS2) and a mixed orthophthalic DCPD low styrene and low emission polyester (LES2). Five layers of rovimat reinforcement (each $500 \mathrm{~g} / \mathrm{m}^{2}$ woven roving, $300 \mathrm{~g} / \mathrm{m}^{2}$ mat) resulted in a material typical of those employed for small pleasure boats, with fibre volume contents between 28 and $32 \%$.

Several drop heights were used, from 0.2 to 1.9 meters, to vary impact energy from 3 to $30 \mathrm{~J}$. One panel was tested at each height except for the $16 \mathrm{~J}$ impact, for which two panels were impacted. Tests on the SO2 and LES2 panels were instrumented. The impact force $F$ is obtained from the mass of the impacter $m$ and the acceleration $\gamma$ using the expression: $F=m \gamma$. The ultrasonic C-scan maps allow damaged areas to be quantified. Table 8 presents the results, Figure 8 shows the delaminated area as a function of impact energy.

The results from ultrasonic inspection show significant differences, the reduced styrene resin composites LS2 and LES2 revealing larger projected damage areas than the reference SO2. Two zones can be distinguished. In the first, damage initiates and the delaminated area increases rapidly with impact energy up to around $8 \mathrm{~J}$. Then above this energy the projected 
damage areas increase linearly with impact energy. For the RS materials the slope is steeper than for the SO2 composite.

Figure 9 shows an example of the result of the impact at $16 \mathrm{~J}$ for two resins. Viewed from above the photographs and C-scan maps indicate that the sample with the matrix resin LES2 is more extensively damaged than the standard resin SO2. Polished sections of the samples show the complex nature of the through-thickness damage. The damaged zones differ, for the SO2 resin a classical conical zone is observed involving delaminations but also many intralaminar shear cracks, whereas for the LES2 resin there are mostly delaminations and very few transverse cracks. From these photos of polished sections it is possible to evaluate the true delaminated area (as opposed to the projected area from ultrasonic C-scan) for each material. For the $16 \mathrm{~J}$ impact this indicates an area of around $1950 \mathrm{~mm}^{2}$ for SO2 and 3100 $\mathrm{mm}^{2}$ for LES2, (this is about three times the projected areas for both materials).

These results suggest that the delamination resistance measurements in mode I fracture tests may provide a useful indication of the plate impact performance: there is little difference in initiation of damage in the plates $\left(G_{I c}\right.$ values were similar) but propagation is considerably easier in the low styrene resin composite as reflected by lower $G_{I p}$ values. Mode II delamination tests do not appear to correlate with impact damage for these materials though in published work on aerospace materials a correlation has been noted [e.g. 30]. Damage is primarily the result of delamination growth in the low styrene materials, while in the tougher material higher resistance to delamination results in other intralaminar damage mechanisms. 


\section{Conclusion}

The results shown above indicate first that the reduced styrene emission polyester resins, with lower molecular weight than their traditional counterparts, are all more brittle. This brittle behaviour is not revealed in the tests traditionally used for composite quality control, which measure interlaminar shear and tensile strength, and may explain why the mechanical properties of these materials have not been extensively studied to date. However, tests which reveal the resistance of these materials to intralaminar and interlaminar damage, namely first damage in tension and delamination strain energy release rate, indicate easier damage initiation and propagation for the reduced styrene matrix composites. Drop weight impact tests have also shown more extensive damage zones in composites with reduced styrene content resins. While it might have been suggested that this be due to a weaker fibre/matrix interface compared to traditional resins microdroplet test results indicate a more resistant interface between glass fibres and the low styrene resins. It is indeed the resin brittleness which causes low damage resistance and this should be addressed both in designing with these materials and in adopting more appropriate tests to measure this property.

\section{Acknowledgments}

The authors acknowledge the support of the FIN (Fédération des Industries Nautiques) and the Bretagne region for the PhD work of Yves Perrot. The contribution of Luc Riou of Ifremer to the impact studies is also gratefully acknowledged. 


\section{References}

1. Baley, C., Perrot, Y., Davies, P., Bourmaud, A., Grohens, Y.: Mechanical properties of composites based on low styrene emission polyester resins for marine applications. Applied composite Materials 13, 1-22 (2006)

2. ISO 135 86: Plastics - Determination of fracture toughness (GIC and KIC) - Linear elastic fracture mechanics (LEFM) approach. (2000)

3. Williams, J.G.: Stress analysis of polymers. Ellis Horwood series in engineering science, $2^{\text {nd }}$ ed.

4. Miller, B., Muri, P., Rebenfeld, L.: A microbond method for determination of the shear strength of a fibre/resin interface. Composites Science and Technology 28, 17-32 (1987)

5. Scheer, R.J., and Nairn J.A.: A comparison of several fracture mechanics methods for measuring interfacial toughness with microbond tests. Journal of Adhesion 53, 45-68 (1995)

6. ISO 15024 - 2001: Fibre-reinforced plastic composites - Determination of mode I interlaminar fracture toughness, $\mathrm{G}_{\mathrm{IC}}$, for unidirectionally reinforced materials.

7. Berry, J.P.: Determination of fracture surface energies by the cleavage technique. Journal of Applied Physics 34 (1963)

8. Martin, R.H., and Davidson, B.D.: Mode II fracture toughness evaluation using a four point bend end notched flexure test. In: $4^{\text {th }}$ International on Deformation and Fracture of Composites, Manchester, pp. 243-252 (1997)

9. Compston, P., Jar, P.-Y.B., Davies, P.: Matrix effect on the static and dynamic interlaminar fracture toughness of glass-fiber marine composites. Composites, Part B 29B, 505-516 (1998)

10. Baley, C., Davies, P., Grohens, Y., Dolto, G.: Application of interlaminar tests to marine composites. A review. Applied Composite Materials 11, 96-126 (2004)

11. Diran, X., Hilaire, B., Soulier, J.P., Nardin, M.: Interfacial shear strength in glass-fibre/vinylester-resin composites. Composites Science and Technology 56, 533-539 (1996)

12. Venkatakrishnaiah, S. and Dharani, L.R.: Interfacial stresses in a microbond pull-out specimen. Eur. J. Mech. A/Solids 13, 311-325 (1994)

13. Liu, CH. and Nairn, J.A.: Analytical and experimental methods for a fracture mechanics interpretation of microbond test including the effects of friction and thermal stresses. International journal of adhesion and adhesives 19, 59-70 (1999) 
14. Ash, J.T., Cross, W.M., Svalstad, D., Kellar, J.J., and Kjerengtroen, L.: Finite element evaluation of the microbond test : meniscus effect, interphase region, and vise angle. Composites Science and Technology 63, 641-651 (2003)

15. Roselli, F., and Santare, M.H.: Comparison of the short beam shear (SBS) and interlaminar shear device (ISD) Tests. Composites Part A 28A, 587-594 (1997)

16. Hoecker, F. , Friedrich, K. , Blumberg, H. , Karger-Kocsis, J.: Effects of fiber / matrix adhesion on off-axis mechanical response in carbon-fiber / epoxy-resin composites. Composites Science and Technology 54, 317-327 (1995)

17. Herrera-Franco, P.J., and Drazl, L.T.: Comparison of methods for the measurement of fibre/matrix adhesion in composites. Composites 23, 2-27 (1992)

18. Davies, P. and Petton, D.: An experimental study of scale effects in marine composites. Composites Part A 30, 267-275 (1999)

19. Meraghni, F. and Benzeggagh, M.L.: Micromechanical modelling of matrix degradation in randomly oriented discontinuous-fibre composites. Composites Science and Technology 55, 171-186 (1995)

21. Yamini, S., Young, R.J.: Stability of crack propagation in epoxy resins. Polymer 18, 1075-1080 (1977)

22. Kinloch, A.J., Williams, J.G.: Crack blunting mechanisms in polymers. Journal of Materials Science 15, $987-$ $996(1980)$

23. Brunellière, O., Davies, P.: Effects of defects on interlaminar fracture of glass fibre reinforced polyester composites. J. Materials Science Letters 12, 427-429 (1993)

24. Davies, P., Cantwell, W., Moulin, C., Kausch, H.H.: A study of the delamination resistance of IM6/PEEK composites. Composites Science and Technology 36, 153-166 (1989)

25. Prel, Y.J., Davies, P., Benzeggagh, M.L., De Charentenay, F.X.: Mode I and mode II delamination of thermosetting and thermoplastic composites. In: $2^{\text {nd }}$ ASTM Symposium on Fatigue and Fracture, Cincinnati, ASTM STP 1012, pp. 69-251 (1989)

26. Feih, S., Wei, J., Kingshott, P., Sorensen, B.F.: The influence of fibre sizing on the strength and fracture toughness of glass fibre composites. Composites Part A 36, 245-255 (2005)

27. Davies, P., Blackman, B.R.K., Brunner, A.J.: Standard test methods for delamination resistance of composite materials : current status. Appl. Comp. Mats. 5, 345-364 (1998) 
28. Hunston, D.L.: Composite Interlaminar Fracture : Effect of matrix fracture energy. Comp. Tech. Review, ASTM 6, 4, 176-180 (1984)

29. Yee, A.F.: Modifying matrix materials for tougher composites. In: Johnston, N.J. (ed) ASTM STP 937, pp. 383-396 (1987)

30. Masters, J.E.: Correlation of impact and delamination resistance in interleafed laminates. In: Proc. ICCM6 vol. 3, pp. 96-107 (1987) 


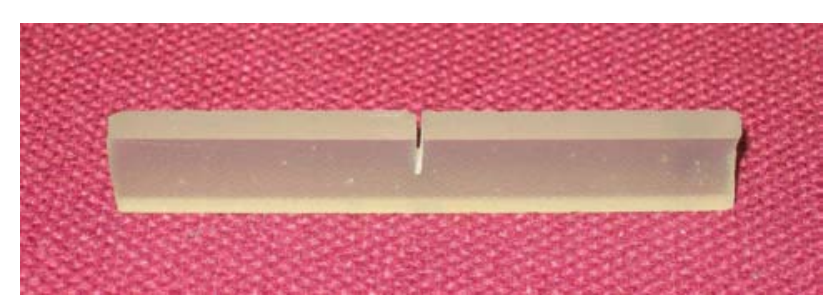

Figure 1. Notched resin specimen. 


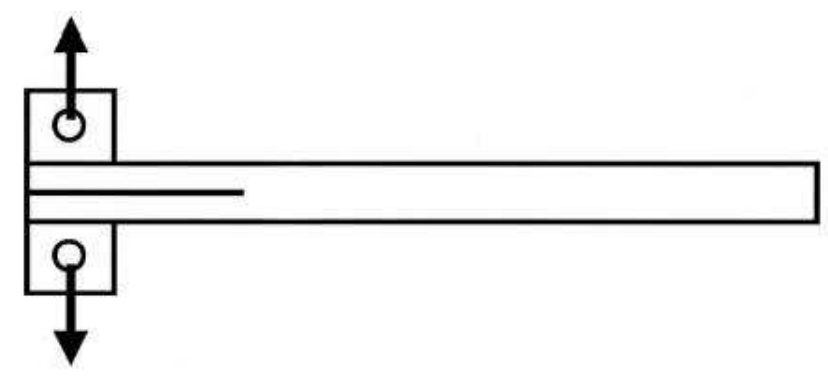

Figure 2a. Mode I DCB specimen. 


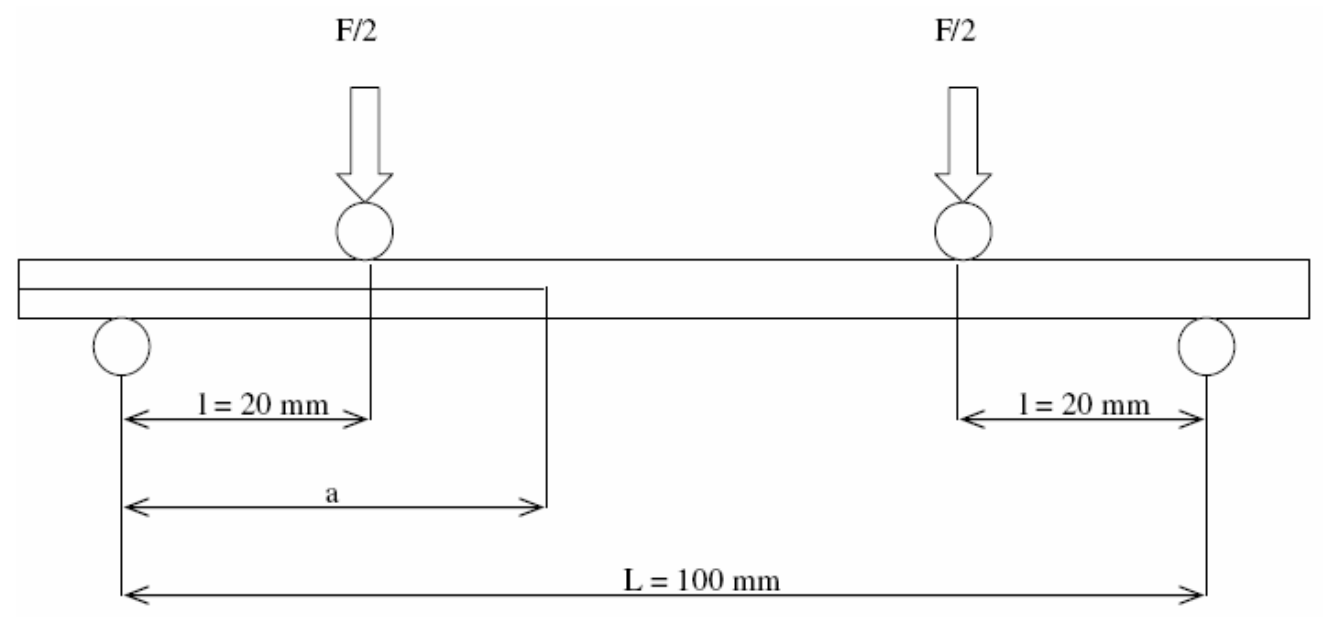

Figure 2b. Mode II 4ENF specimen. 

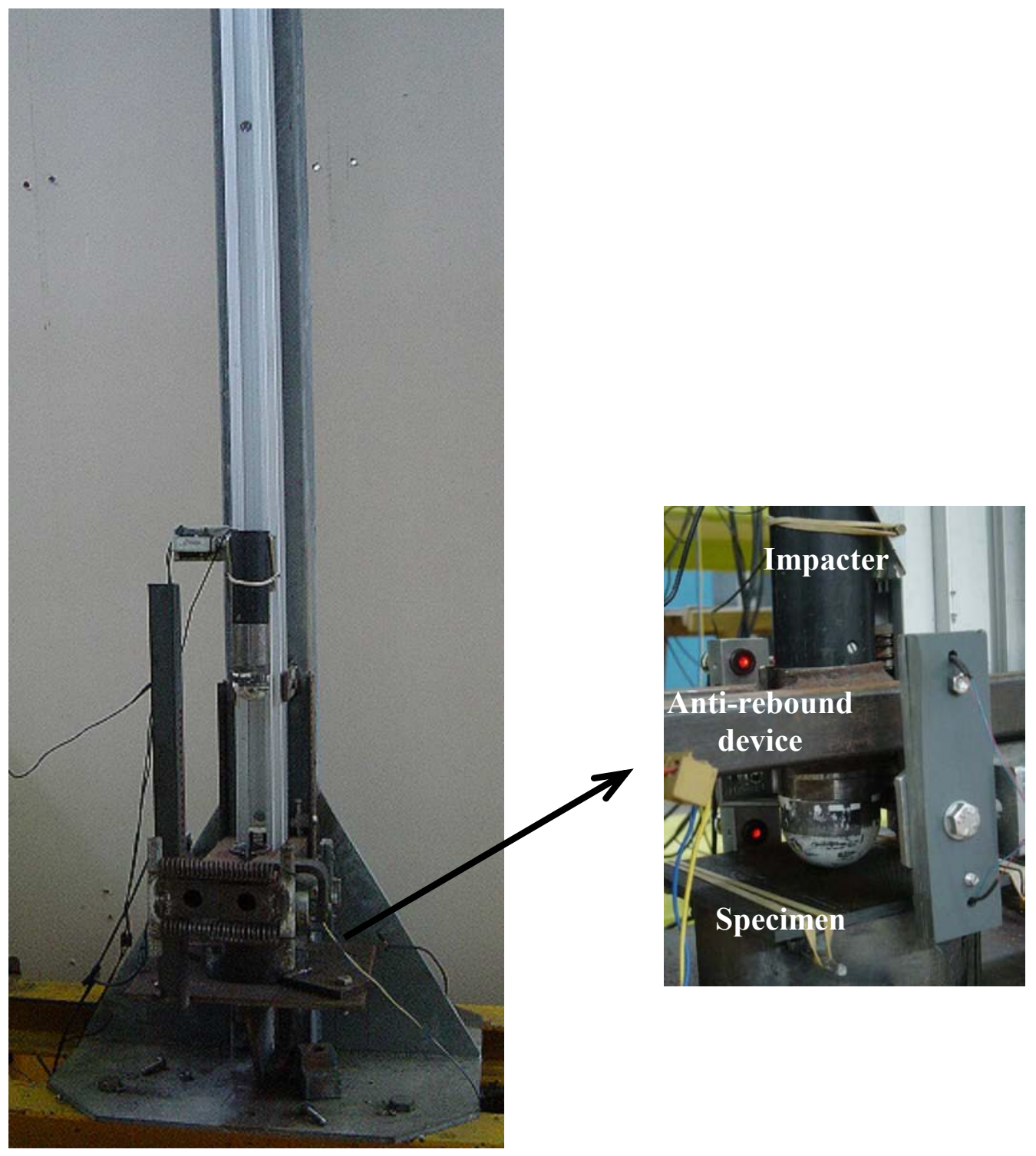

Figure 3. Impact test set-up. Insert shows impacter above panel, and IR sensors. 


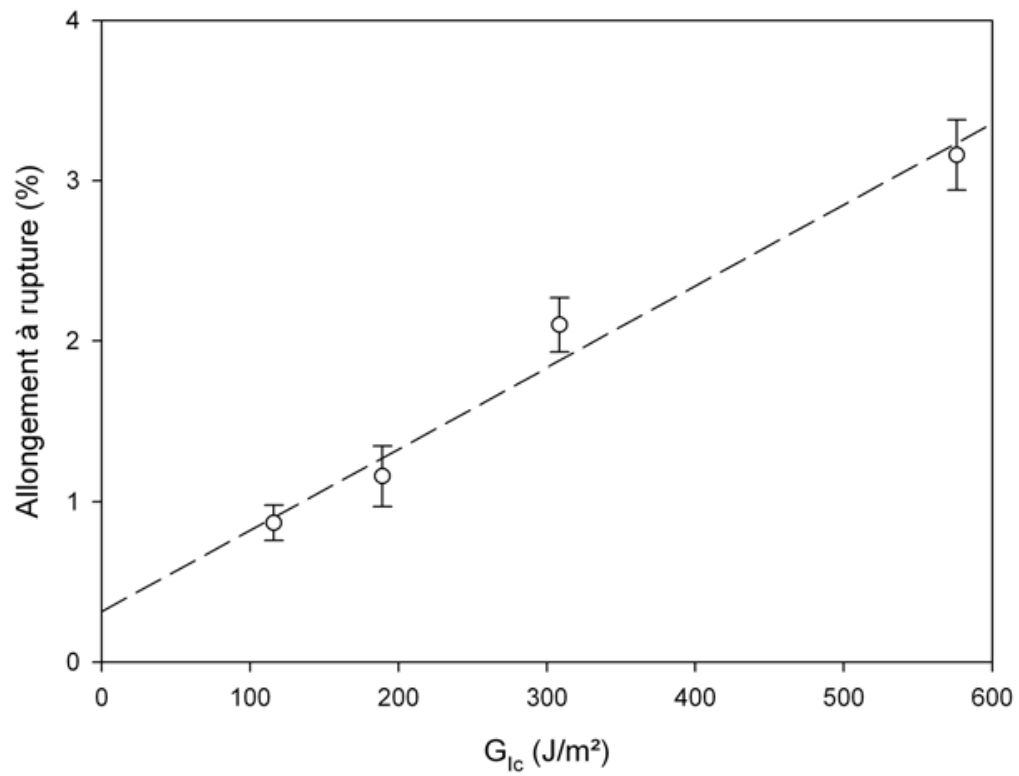

Figure 4. Relation between failure strain and apparent $G_{l c}$. 


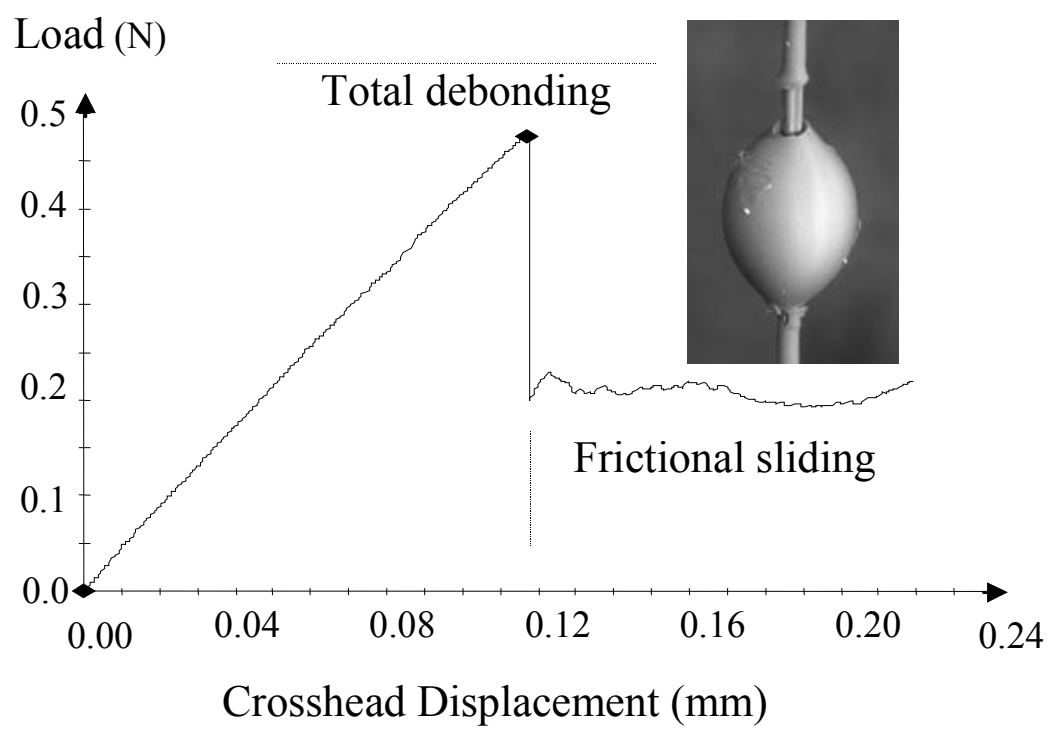

Figure 5. Example of load- displacement plot for microdroplet test. 


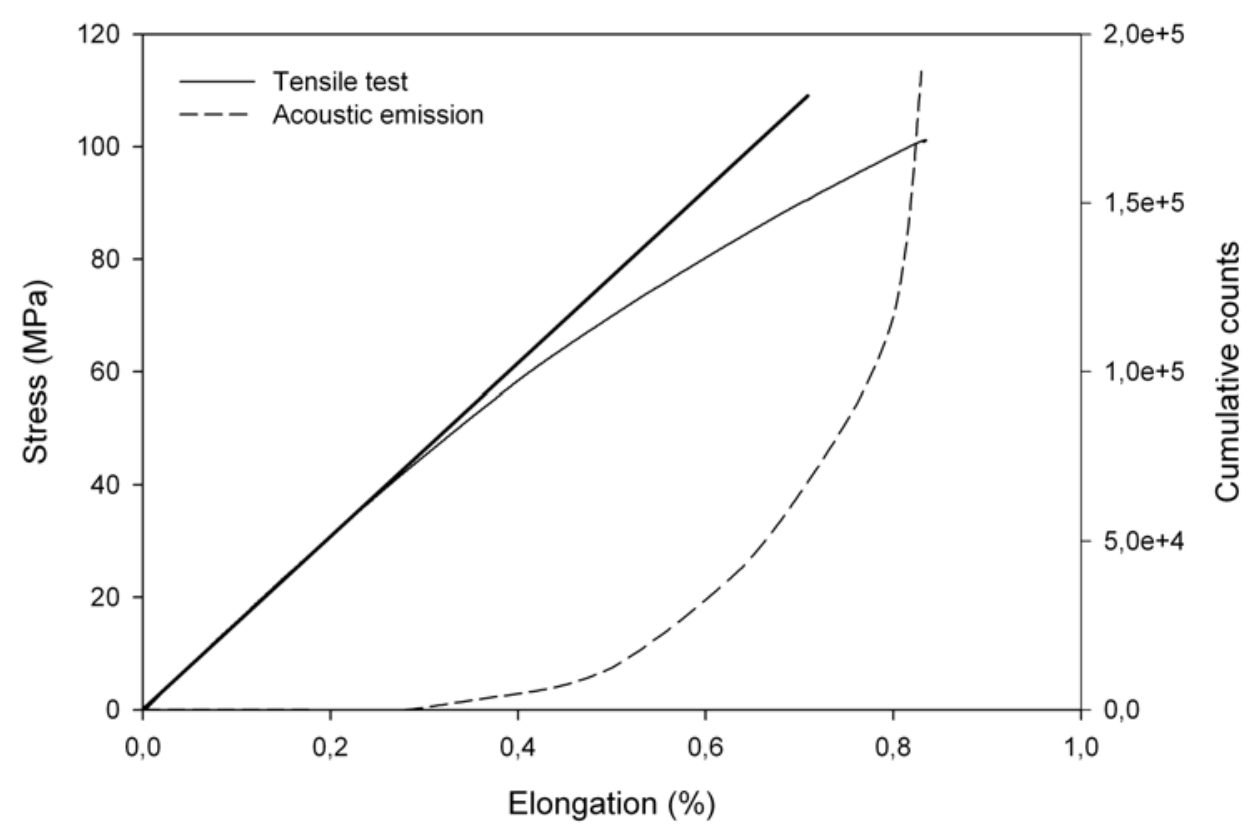

Figure 6. Stress-strain plot for tensile test on mat reinforced polyester, with acoustic emission recording superposed. 


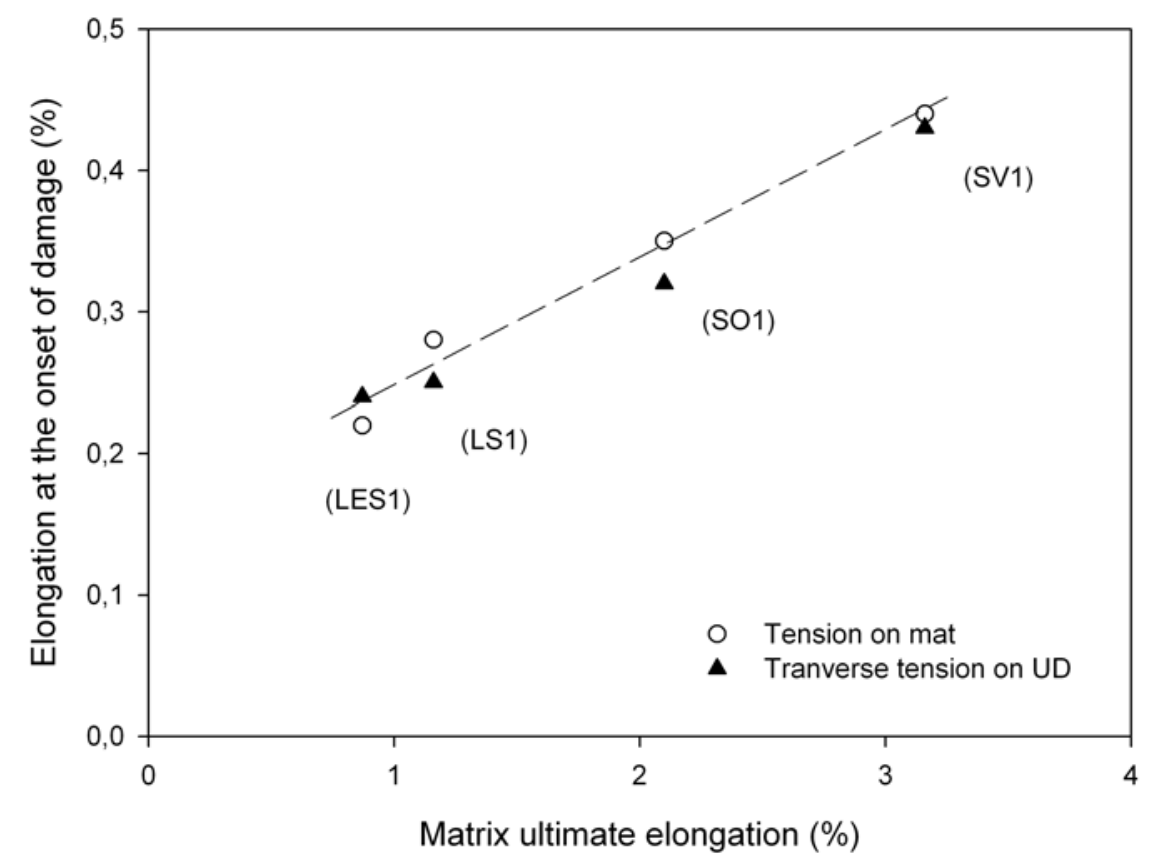

Figure 7. Glass/polyester laminate. Elongation at the onset of damage as a function of matrix ultimate elongation. 


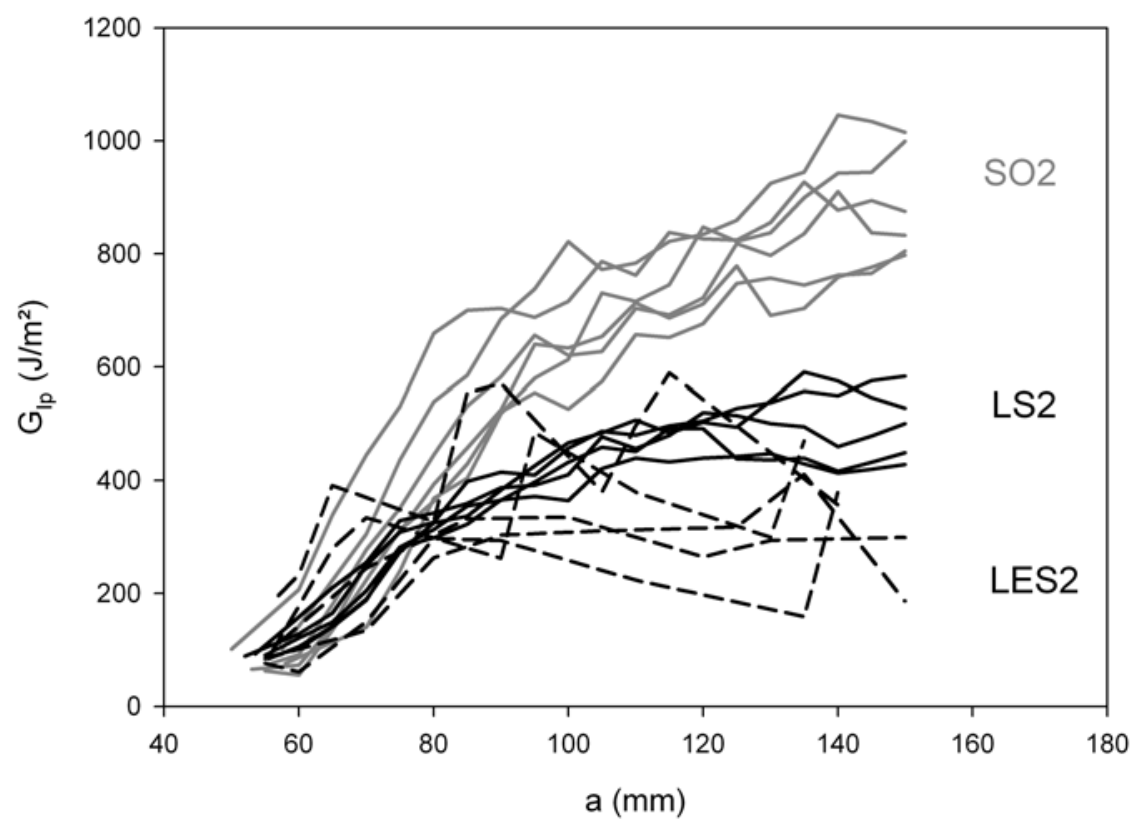

Figure 8. R-curves showing $G_{l p}$ versus measured crack length. 


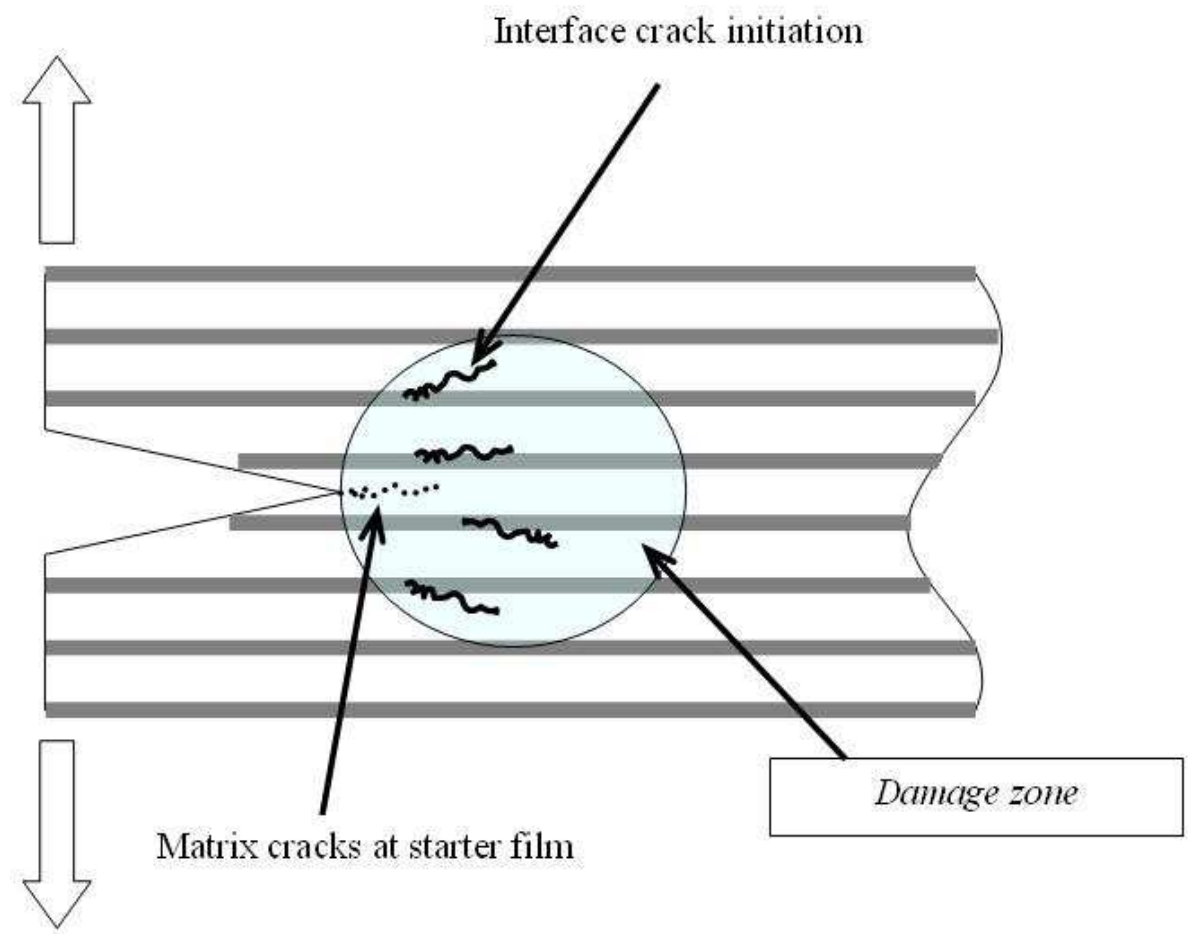

Figure 9. Schematic figure showing damage zone 


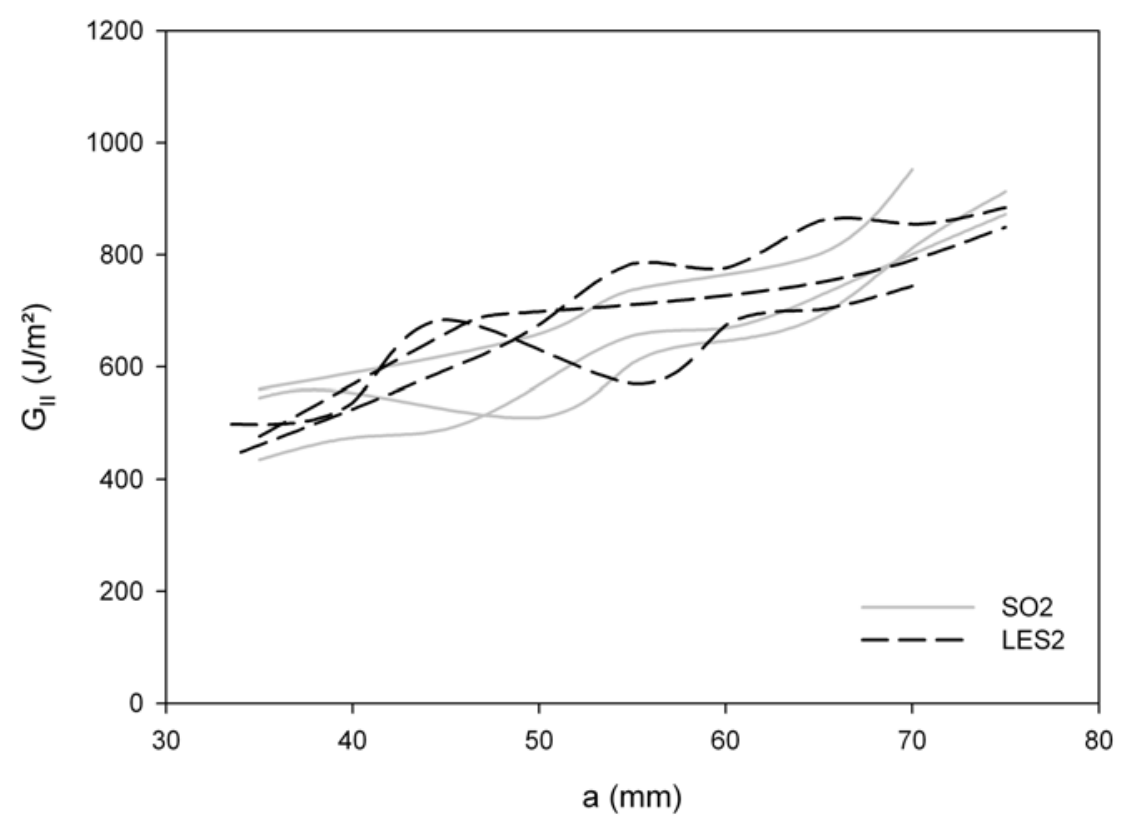

Figure 10. Mode II Rcurves 


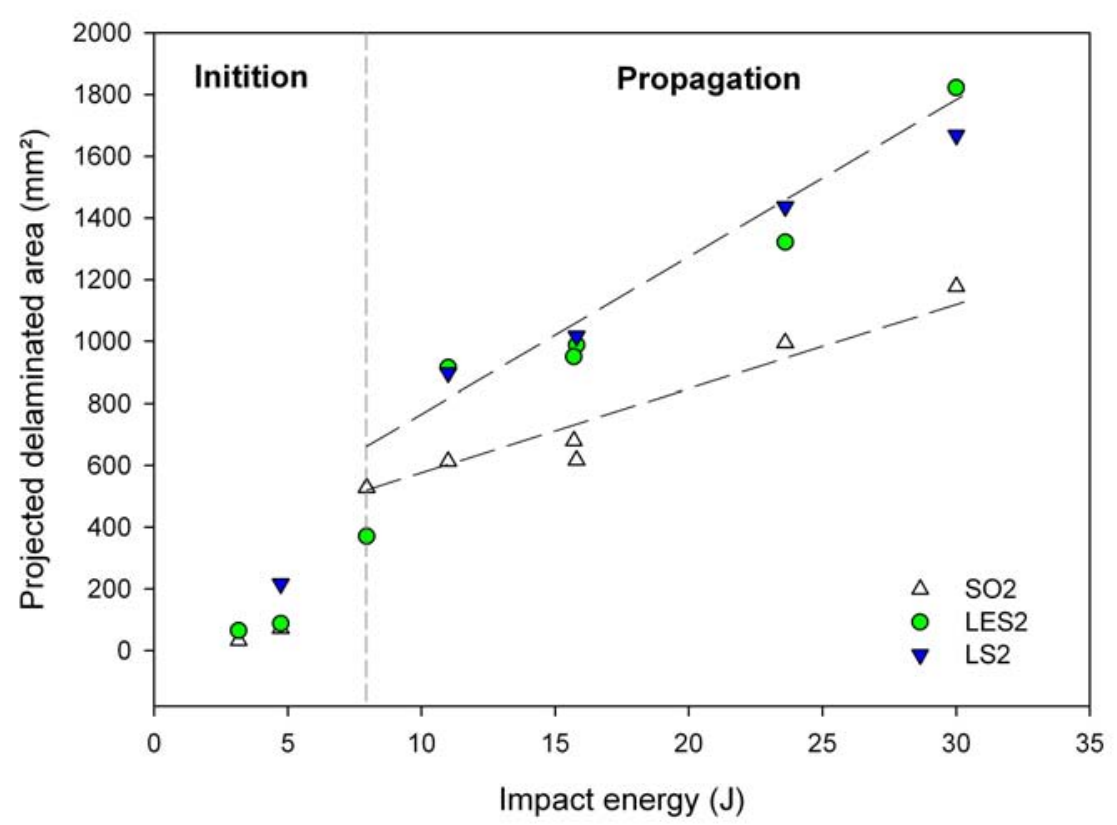

Figure 11. Projected delaminated areas versus impact energy. 


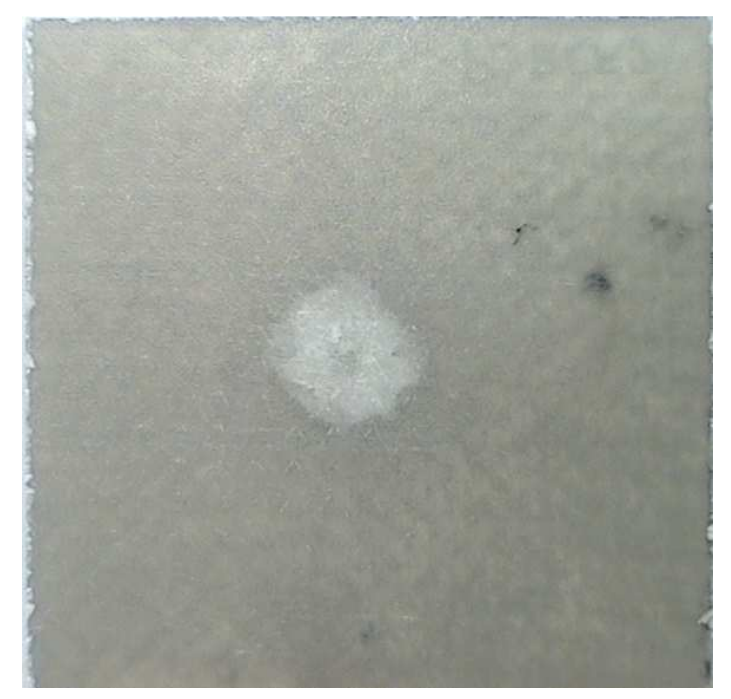

SO2 $16 \mathrm{~J}$ impact

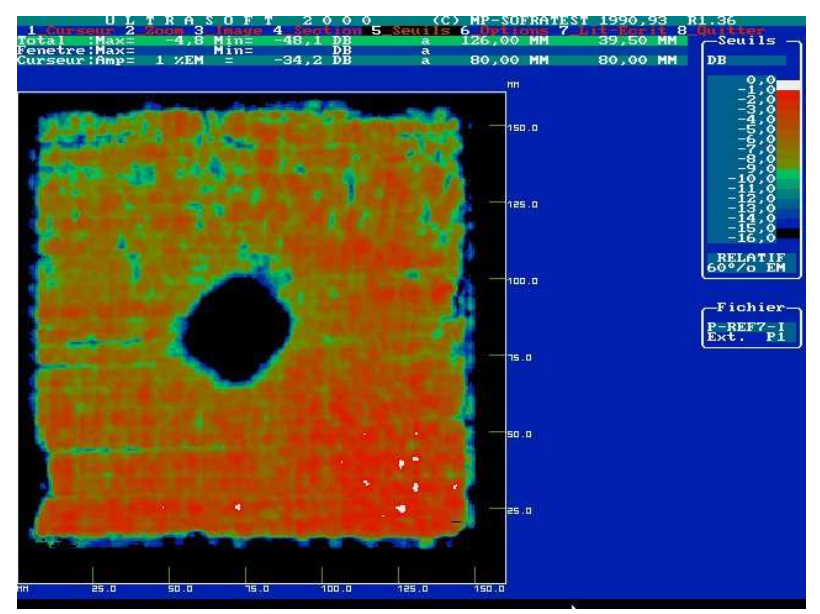

SO2 -US C-scan

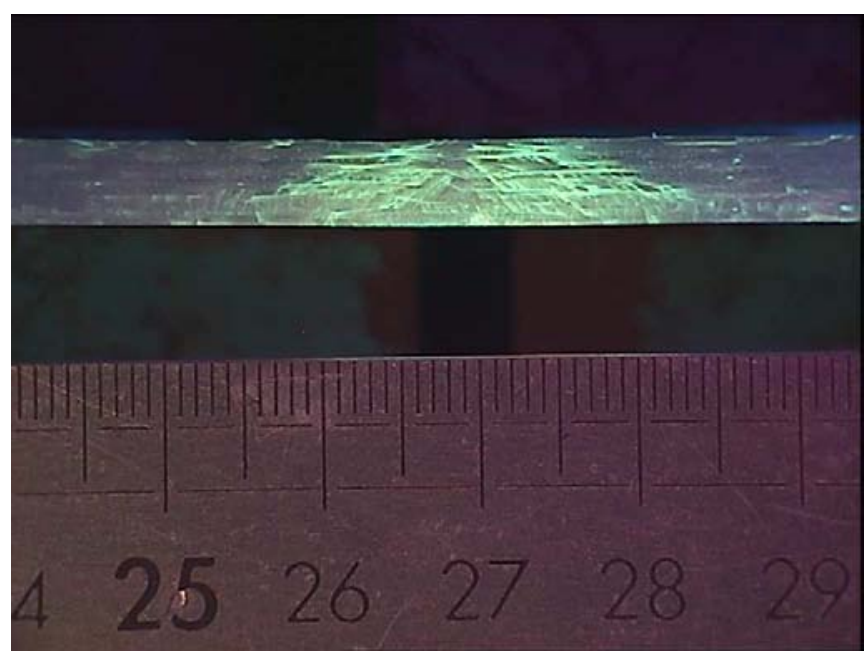

SO2 - Damage through thickness

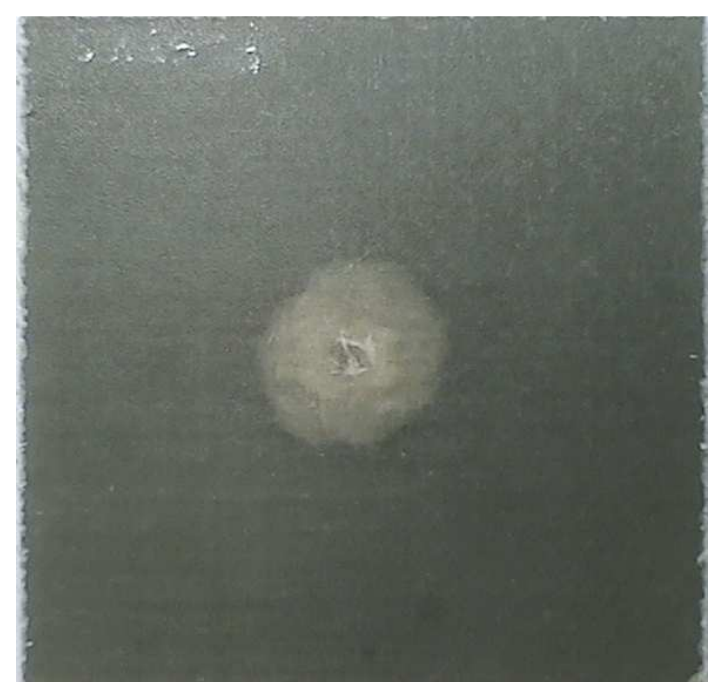

LES2 -16 J impact

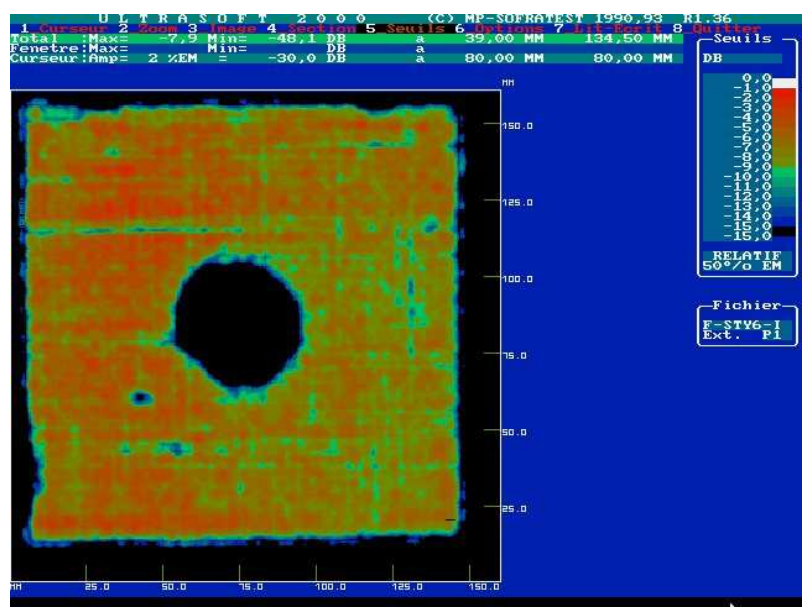

LES2 - US C-scan

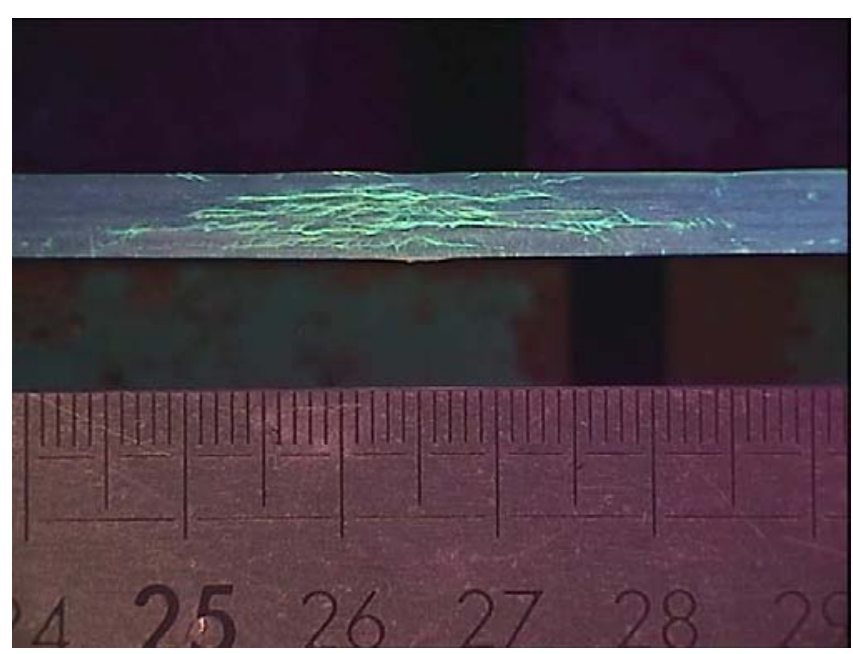

LES2 - Damage through thickness

Figure 12. Damage in panels after $16 \mathrm{~J}$ impact. 


\begin{tabular}{lccccc}
\hline Resin & $\begin{array}{c}\text { Styrene content } \\
(\text { wt } \%)\end{array}$ & $\begin{array}{c}\text { Tensile Modulus } \\
(\mathrm{MPa})\end{array}$ & $\begin{array}{c}\text { Tensile failure } \\
\text { stress }(\mathrm{MPa})\end{array}$ & $\begin{array}{c}\text { Failure strain } \\
(\%)\end{array}$ \\
\cline { 2 - 6 } & $\mathrm{SO} 1$ & 42 & $3077 \pm 192$ & $49 \pm 7$ & $2.1 \pm 0.5$ \\
\cline { 2 - 6 } $\mathrm{RS}$ & $\mathrm{SO} 2$ & 49 & $3707 \pm 162$ & $49 \pm 10$ & $1.6 \pm 0.5$ \\
\cline { 2 - 6 } $\mathrm{RS}$ & LS1 & $35-38$ & $3120 \pm 188$ & $30 \pm 7$ & $1.2 \pm 0.4$ \\
\cline { 2 - 6 } $\mathrm{RS}$ & LS2 & 38 & $3227 \pm 83$ & $38 \pm 3$ & $1.4 \pm 0.2$ \\
\cline { 2 - 6 } $\mathrm{RS}$ & LES1 & $37-39$ & $3295 \pm 54$ & $25 \pm 3$ & $0.9 \pm 0.1$ \\
\cline { 2 - 6 } & LES2 & 28 & $2729 \pm 45$ & $19 \pm 2$ & $0.8 \pm 0.1$ \\
\cline { 2 - 6 } & SV1 & $48-51$ & $2901 \pm 125$ & $60 \pm 2$ & $3.2 \pm 0.2$ \\
\cline { 2 - 6 }
\end{tabular}

Table 1. Resin properties [1]. 


\begin{tabular}{ccc}
\hline Resin & $\begin{array}{c}\mathrm{K}_{\mathrm{Ic}} \\
\left(\mathrm{MPa} . \mathrm{m}^{1 / 2}\right)\end{array}$ & $\begin{array}{c}\mathrm{G}_{\mathrm{Ic}} \\
\left(\mathrm{J} / \mathrm{m}^{2}\right)\end{array}$ \\
\hline SO1 & $1.04 \pm 0.05$ & $308 \pm 34$ \\
\hline LS1 & $0.82 \pm 0.12$ & $189 \pm 39$ \\
\hline LES1 & $0.66 \pm 0.05$ & $116 \pm 11$ \\
\hline SV1 & $1.38 \pm 0.17$ & $576 \pm 96$ \\
\hline
\end{tabular}

Table 2. Apparent fracture toughness of four marine resins. 


\begin{tabular}{lcccc}
\cline { 2 - 4 } & SO1 & LS1 & LES1 & SV1 \\
\hline $\begin{array}{l}\text { Ratio of Bonded length } / \\
\text { Droplet diameter }\end{array}$ & $1.4 \pm 0.1$ & $1.5 \pm 0.1$ & $1.5 \pm 0.2$ & $1.8 \pm 0.1$ \\
\hline $\begin{array}{l}\tau_{a p p} \text { mean } \\
(\mathrm{MPa})\end{array}$ & $12.0 \pm 2.9$ & $19.3 \pm 3.2$ & $22.4 \pm 1.4$ & $8.5 \pm 1.0$ \\
\hline $\begin{array}{l}\tau_{\text {app }} \text { regression } \\
(\mathrm{MPa})\end{array}$ & $12.3 \pm 2.2$ & $19.4 \pm 2.9$ & $22.6 \pm 1.2$ & $8.4 \pm 0.9$ \\
\hline$G_{i c}$ & $17.7 \pm 7.2$ & $30.9 \pm 5.7$ & $61.7 \pm 20.7$ & $9.3 \pm 2.1$ \\
$\left(\mathrm{~J} / \mathrm{m}^{2}\right)$ & & & & \\
\hline
\end{tabular}

Table 3. Results from microdroplet debond tests. 


\begin{tabular}{cccc}
\hline \multirow{2}{*}{$\begin{array}{c}\text { Stacking } \\
\text { sequence }\end{array}$} & Resin & $\begin{array}{c}\text { Fibre content } V_{f} \\
(\%)\end{array}$ & $\begin{array}{c}\text { ILSS } \\
(\mathrm{MPa})\end{array}$ \\
\hline \multirow{2}{*}{ UD } & SO2 & 48.5 & $27 \pm 1$ \\
\cline { 2 - 4 } & LS2 & 47.7 & $33 \pm 2$ \\
\cline { 2 - 4 } & LES2 & 50.0 & $28 \pm 3$ \\
\hline \multirow{2}{*}{ Mat/Woven } & SO1 & 26.9 & $21 \pm 1$ \\
\cline { 2 - 4 } & LS1 & 25.9 & $20 \pm 1$ \\
\cline { 2 - 4 } & LES1 & 25.2 & $21 \pm 1$ \\
\hline
\end{tabular}

Table 4. Apparent ILSS for two sets of materials. 


\begin{tabular}{|c|c|c|c|c|c|}
\hline & & & & & \\
\hline & & SO1 & LS1 & LES1 & SV1 \\
\hline \multirow{2}{*}{ Matrix } & Young's modulus (MPa) & $3077 \pm 192$ & $3120 \pm 188$ & $3295 \pm 54$ & $2901 \pm 125$ \\
\hline & Failure strain (\%) & $2.1 \pm 0.5$ & $1.2 \pm 0.2$ & $0.9 \pm 0.1$ & $3.2 \pm 0.2$ \\
\hline \multirow{8}{*}{$\begin{array}{l}\text { Composite } \\
\text { reinforced by glass } \\
\text { mat }\end{array}$} & Fibre volume fraction (\%) & 17 & 19 & 18 & 18 \\
\hline & Young's modulus (MPa) & $7560 \pm 420$ & $8171 \pm 444$ & $8111 \pm 332$ & $7405 \pm 436$ \\
\hline & Failure stress (MPa) & $97 \pm 6$ & $104 \pm 9$ & $93 \pm 9$ & $104 \pm 8$ \\
\hline & Failure strain (\%) & $0.79 \pm 0.07$ & $0.85 \pm 0.10$ & $0.72 \pm 0.11$ & $0.86 \pm 0.08$ \\
\hline & Stress at first AE. (MPa) & $52 \pm 3$ & $42 \pm 4$ & $36 \pm 6$ & $62 \pm 3$ \\
\hline & Stress AE / Failure stress & 0.54 & 0.40 & 0.38 & 0.59 \\
\hline & Strain at first AE (\%) & $0.35 \pm 0.02$ & $0.28 \pm 0.02$ & $0.22 \pm 0.03$ & $0.44 \pm 0.01$ \\
\hline & Strain AE / Failure strain & 0.44 & 0.39 & 0.30 & 0.51 \\
\hline \multirow{3}{*}{$\begin{array}{c}\text { UD transverse } \\
\text { tension [1] }\end{array}$} & Fibre volume fraction & 39 & 37 & 38 & 38 \\
\hline & Failure stress $(\mathrm{MPa})$ & $18.3 \pm 0.76$ & $17.7 \pm 0.6$ & $18.4 \pm 1.4$ & $27.8 \pm 0.8$ \\
\hline & Failure strain (\%) & $0.32 \pm 0.3$ & $0.25 \pm 0.01$ & $0.24 \pm 0.02$ & $0.4 \pm 0.02$ \\
\hline
\end{tabular}

Table 5. Tensile test monitoring by Acoustic Emission. 


\begin{tabular}{ccc}
\hline Reference & $\begin{array}{c}G_{l c}\left(\mathrm{~J} / \mathrm{m}^{2}\right) \\
\text { Initiation }\end{array}$ & $\begin{array}{c}G_{l c}\left(\mathrm{~J} / \mathrm{m}^{2}\right) \\
\text { Propagation } \\
\text { Crack length } 100 \text { to } 140 \mathrm{~mm}\end{array}$ \\
\hline $\mathrm{SO} 2$ & $81 \pm 17$ & $770 \pm 71$ \\
\hline LS2 & $89 \pm 3$ & $477 \pm 38$ \\
\hline LES2 & $112 \pm 48$ & $342 \pm 156^{*}$ \\
\hline
\end{tabular}

* Unstable propagation

Table 6. $G_{l c}$-of resins reinforced by unidirectional fibres. 


\begin{tabular}{ccc}
\hline Reference & $\begin{array}{c}\mathrm{G}_{1 \mathrm{Ic}}\left(\mathrm{J} / \mathrm{m}^{2}\right) \\
\text { Initiation }\end{array}$ & $\begin{array}{c}\mathrm{G}_{1 \mathrm{Ic}}\left(\mathrm{J} / \mathrm{m}^{2}\right) \\
\text { Propagation } \\
\text { Crack length } 50 \text { to } 70 \mathrm{~mm}\end{array}$ \\
\hline SO2 & $514 \pm 67$ & $708 \pm 70$ \\
\hline LES2 & $475 \pm 25$ & $743 \pm 62$ \\
\hline
\end{tabular}

Table 7. $G_{I I c}$ of resins reinforced by unidirectional fibres. 


\begin{tabular}{|c|c|c|c|c|c|c|c|c|}
\hline \multirow[b]{2}{*}{$\begin{array}{l}\text { Impact height } \\
(\mathrm{mm})\end{array}$} & \multirow[b]{2}{*}{ Energy (J) } & \multicolumn{2}{|c|}{$\begin{array}{c}\text { Impact time } \\
(\mathrm{ms})\end{array}$} & \multicolumn{2}{|c|}{$\begin{array}{c}\text { Impact load } \\
(\mathrm{N})\end{array}$} & \multicolumn{3}{|c|}{$\begin{array}{c}\text { Delaminated area } \\
\left(\mathrm{mm}^{2}\right)\end{array}$} \\
\hline & & $\mathrm{SO} 2$ & LES2 & $\mathrm{SO} 2$ & LES2 & $\mathrm{SO} 2$ & LES2 & LS2 \\
\hline 200 & 3.2 & 4.4 & 4.5 & 332 & 281 & 33 & 65 & - \\
\hline 300 & 4.7 & 3.8 & 5.3 & 489 & 400 & 72 & 88 & 216 \\
\hline 500 & 7.9 & 3.9 & 4.6 & 706 & 527 & 528 & 371 & - \\
\hline 750 & 11.8 & 4.3 & 4.9 & 744 & 694 & 614 & 916 & 898 \\
\hline 997 & 15.7 & 4.2 & 4.5 & 871 & 827 & 605 & 995 & - \\
\hline 1000 & 15.8 & 4.1 & 4.4 & 943 & 831 & 618 & 988 & 1017 \\
\hline 1500 & 23.7 & 4.7 & 4.4 & 1108 & 1106 & 995 & 1322 & 1436 \\
\hline 1900 & 30.0 & 4.5 & 4.3 & 1360 & 1297 & 1178 & 1822 & 1668 \\
\hline
\end{tabular}

Table 8. Impact test results. 